\title{
THE GROWTH CHARTS OF ESTONIAN SCHOOLCHILDREN. COMPARATIVE ANALYSIS
}

\author{
ERIK SALM ${ }^{1}$, ENE KäÄRIK ${ }^{1}$, HelJE KaARMA ${ }^{2}$ \\ ${ }^{1}$ Institute of Mathematical Statistics, University of Tartu, Estonia \\ ${ }^{2}$ Centre for Physical Anthropology, University of Tartu, Estonia
}

\begin{abstract}
The current growth charts of Estonian children are based on the data collected in 1996. The aim of this article is to study whether children still correspond to these norms. For that purpose, an overview is given of the height, weight and body mass index of Estonian schoolchildren. These measurements have been collected mainly from 2006-2009. These data are compared with the results of 1996 by means of statistical tests.

During the interim period, the development of Estonian schoolchildren has changed. Children are significantly taller (boys by $4.84 \mathrm{~cm}$ and girls by $3.86 \mathrm{~cm}$ on average) and heavier (boys by $5.90 \mathrm{~kg}$ and girls by $4.20 \mathrm{~kg}$ on average). The mean body mass index has also increased significantly (in boys by 1.30 units and in girls by 0.99 units on average). In conclusion, it can be said that schoolchildren do not correspond well to the current norms, and the growth charts need updating.
\end{abstract}

Keywords: Estonian schoolchildren, growth charts

\section{INTRODUCTION}

To monitor children's growth, countries with developed medicine have used growth charts for more than 50 years. Body height and weight are some of the most essential indicators of physical development, and visual graphs enable to monitor the child's growth and deviations from normal development. Children's repetitive measuring at regular intervals and comparison of measuring results with the standard facilitates early noticing of growth disorders. A growth disorder can be a manifestation of several diseases, and therefore, finding of 
disorders makes one think about their possible causes. Application of growth charts makes it easier for family physicians, pediatricians, geneticists and other specialists to find children with growth disorders and to monitor their development.

In Estonia, growth charts were first compiled and used in 1993. They were based on cross-sectional and longitudinal measurements of children's height and weight conducted in the 1970s. The norms currently used at schools are based on the data collected in 1996

In addition to watching the correspondence of growth to the norms, children's growth rate should also be monitored. Growth rate is the absolute increase in height during a certain period. In order to obtain more precise assessments, growth rate is measured after relatively long periods, e.g. half a year or a year. Growth rate slows down or accelerates before the child's height passes the limits of the norm, and therefore, this indicator is considered the most informative in assessment of growth disorders. [1]

\section{MATERIAL AND METHODS}

The data include the height and weight measurements of 21764 Estonian children collected mainly from 2006 to 2009. Additionally, the body mass index (BMI) was calculated. All the measurements had been carried out by school physicians and pediatricians earlier in the course of their routine work. For each subject, the birth date and the date of measuring were also recorded. The schools and medical establishments from which the data were collected were selected by random sampling. In total 10282 boys and 11482 girls aged from 6-19 years were measured. In addition to descriptive statistics, the physical development was visualized by centile splines. The 3-, 10-, 25-, 50-, 75-, 90- and 97-percentiles were calculated for each age group and then connected using cubic spline interpolation.

The data were compared to the summary statistics of Estonian children published in 1996 when 17175 children ( 8408 boys and 8767 girls) aged from 6-19 years were measured. Therefore, the 19-year-olds of the newer data set have been left out of the comparison.

To determine the changes in growth curves, the means and standard deviations of body height, body weight and body mass index were compared for each 
age group (from 6 to 18 years). For comparison, the F-test and the t-test using summary statistics were used. For significance level, the familywise error rate of 0.05 was chosen. Using the Bonferroni correction, the difference was statistically significant if $\mathrm{p}$-value was less than 0.00385 .

\section{RESULTS}

The key characteristics (sample size, mean, standard deviation, minimum, maximum) of height, weight and body mass index are presented respectively in Tables 1, 2 and 3.

Table 1. The key characteristics of height according to sex and age group

\begin{tabular}{|c|c|c|c|c|c|c|c|c|c|c|}
\hline \multirow[b]{2}{*}{ Age } & \multicolumn{5}{|c|}{ Girls } & \multicolumn{5}{|c|}{ Boys } \\
\hline & $\begin{array}{l}\text { Sample } \\
\text { size }\end{array}$ & Height & Sd & Min & Max & $\begin{array}{c}\text { Sample } \\
\text { size }\end{array}$ & Height & Sd & Min & Max \\
\hline 6 & 113 & 123.79 & 5.60 & 111.0 & 139.0 & 99 & 125.44 & 5.19 & 113.5 & 137.0 \\
\hline 7 & 1041 & 128.24 & 5.60 & 110.5 & 146.5 & 936 & 129.61 & 5.71 & 111.5 & 150.0 \\
\hline 8 & 667 & 132.89 & 5.92 & 115.3 & 148.8 & 705 & 133.73 & 5.94 & 114.0 & 155.5 \\
\hline 9 & 1063 & 139.45 & 6.44 & 121.0 & 162.0 & 1052 & 139.85 & 6.23 & 119.0 & 162.0 \\
\hline 10 & 450 & 145.13 & 7.47 & 120.5 & 172.0 & 456 & 144.60 & 6.38 & 126.0 & 165.0 \\
\hline 11 & 1298 & 152.16 & 7.28 & 128.5 & 175.0 & 1114 & 151.35 & 7.10 & 129.9 & 175.6 \\
\hline 12 & 536 & 157.70 & 6.90 & 134.0 & 173.0 & 569 & 156.23 & 7.98 & 134.0 & 183.5 \\
\hline 13 & 1355 & 163.39 & 6.43 & 141.0 & 183.5 & 1227 & 165.51 & 8.73 & 140.0 & 193.0 \\
\hline 14 & 637 & 165.20 & 6.54 & 143.5 & 185.0 & 680 & 169.62 & 8.65 & 142.7 & 195.0 \\
\hline 15 & 1829 & 167.13 & 5.95 & 149.3 & 188.0 & 1596 & 176.75 & 7.34 & 151.5 & 200.0 \\
\hline 16 & 978 & 167.63 & 6.24 & 149.5 & 189.0 & 831 & 178.55 & 7.10 & 154.5 & 200.0 \\
\hline 17 & 588 & 168.62 & 5.88 & 150.0 & 188.0 & 373 & 180.82 & 6.24 & 162.0 & 202.0 \\
\hline 18 & 762 & 168.23 & 5.88 & 149.0 & 184.0 & 523 & 181.28 & 6.53 & 160.0 & 200.1 \\
\hline 19 & 165 & 168.25 & 5.94 & 152.5 & 181.5 & 121 & 182.57 & 6.53 & 166.4 & 198.0 \\
\hline
\end{tabular}


Table 2. The key characteristics of weight according to sex and age group

\begin{tabular}{c|ccccc|ccccc}
\hline \multirow{2}{*}{ Age } & \multicolumn{5}{|c|}{ Girls } & \multicolumn{5}{c}{ Boys } \\
\cline { 2 - 11 } & $\begin{array}{c}\text { Sample } \\
\text { size }\end{array}$ & Weight & Sd & Min & Max & $\begin{array}{c}\text { Sample } \\
\text { size }\end{array}$ & Weight & Sd & Min & Max \\
\hline 6 & 113 & 24.46 & 3.73 & 18.0 & 34.0 & 99 & 25.45 & 4.32 & 18.0 & 41.0 \\
\hline 7 & 1041 & 27.05 & 4.85 & 15.8 & 44.5 & 936 & 28.30 & 5.16 & 13.3 & 49.0 \\
\hline 8 & 667 & 29.73 & 5.65 & 18.0 & 47.4 & 705 & 30.51 & 5.93 & 19.5 & 55.5 \\
\hline 9 & 1063 & 33.83 & 6.75 & 16.5 & 57.0 & 1052 & 34.70 & 7.19 & 19.0 & 63.0 \\
\hline 10 & 450 & 37.88 & 8.89 & 20.4 & 69.0 & 456 & 38.76 & 8.63 & 24.9 & 65.0 \\
\hline 11 & 1298 & 43.13 & 9.28 & 21.0 & 75.5 & 1114 & 43.24 & 9.74 & 26.0 & 84.0 \\
\hline 12 & 536 & 47.77 & 9.76 & 26.0 & 80.7 & 569 & 46.91 & 10.36 & 25.1 & 84.0 \\
\hline 13 & 1355 & 53.26 & 9.56 & 30.0 & 87.0 & 1227 & 55.06 & 11.81 & 28.0 & 95.5 \\
\hline 14 & 637 & 55.38 & 10.01 & 33.2 & 87.2 & 680 & 58.59 & 11.56 & 29.7 & 98.5 \\
\hline 15 & 1829 & 58.44 & 8.90 & 32.7 & 91.2 & 1596 & 65.84 & 10.94 & 35.8 & 103.0 \\
\hline 16 & 978 & 58.87 & 8.35 & 35.5 & 88.5 & 831 & 67.59 & 10.59 & 40.0 & 104.0 \\
\hline 17 & 588 & 60.84 & 8.57 & 43.0 & 91.5 & 373 & 71.50 & 11.10 & 47.0 & 107.0 \\
\hline 18 & 762 & 60.76 & 9.15 & 41.0 & 93.0 & 523 & 74.12 & 11.06 & 47.0 & 110.0 \\
\hline 19 & 165 & 61.51 & 9.18 & 44.5 & 88.6 & 121 & 73.86 & 9.10 & 50.0 & 104.0 \\
\hline & & & & & & & & & &
\end{tabular}

Table 3. The key characteristics of body mass index according to sex and age group

\begin{tabular}{c|ccccc|ccccc}
\hline \multirow{2}{*}{ Age } & \multicolumn{9}{|c|}{ Girls } & \multicolumn{5}{c}{ Boys } \\
\cline { 2 - 11 } & $\begin{array}{c}\text { Sample } \\
\text { size }\end{array}$ & BMI & Sd & Min & Max & $\begin{array}{c}\text { Sample } \\
\text { size }\end{array}$ & BMI & Sd & Min & Max \\
\hline 6 & 113 & 15.91 & 1.75 & 12.39 & 21.29 & 99 & 16.08 & 1.82 & 12.50 & 22.38 \\
\hline 7 & 1041 & 16.36 & 2.17 & 10.33 & 23.89 & 936 & 16.75 & 2.20 & 8.79 & 24.82 \\
\hline 8 & 667 & 16.75 & 2.39 & 11.42 & 25.13 & 705 & 16.97 & 2.43 & 12.08 & 26.02 \\
\hline 9 & 1063 & 17.29 & 2.57 & 8.86 & 26.66 & 1052 & 17.62 & 2.70 & 10.74 & 27.74 \\
\hline 10 & 450 & 17.82 & 3.07 & 12.57 & 27.78 & 456 & 18.42 & 3.23 & 13.13 & 28.15 \\
\hline 11 & 1298 & 18.49 & 3.04 & 11.19 & 29.34 & 1114 & 18.74 & 3.25 & 13.04 & 31.18 \\
\hline 12 & 536 & 19.08 & 3.00 & 12.96 & 29.36 & 569 & 19.07 & 3.18 & 12.72 & 30.70 \\
\hline 13 & 1355 & 19.88 & 3.03 & 12.98 & 31.22 & 1227 & 19.95 & 3.20 & 12.91 & 31.62 \\
\hline 14 & 637 & 20.24 & 3.16 & 14.18 & 31.25 & 680 & 20.25 & 3.10 & 14.19 & 31.12 \\
\hline 15 & 1829 & 20.90 & 2.82 & 13.35 & 31.44 & 1596 & 21.01 & 2.85 & 14.28 & 31.67 \\
\hline 16 & 978 & 20.93 & 2.61 & 13.61 & 30.09 & 831 & 21.15 & 2.76 & 15.27 & 30.94 \\
\hline 17 & 588 & 21.38 & 2.67 & 15.89 & 30.86 & 373 & 21.82 & 2.89 & 15.27 & 32.43 \\
\hline 18 & 762 & 21.43 & 2.79 & 15.37 & 31.14 & 523 & 22.52 & 2.92 & 16.07 & 33.46 \\
\hline 19 & 165 & 21.68 & 2.68 & 16.96 & 30.45 & 121 & 22.15 & 2.45 & 15.87 & 30.30 \\
\hline & & & & & & & & & &
\end{tabular}


Centile splines. The graphs of boys' and girls' centile splines of height, weight and BMI are presented in Figures 1,2 and 3. In all the figures, the centile lines correspond to percentiles $3,10,25,50,75,90$ and 97 . They give a good visual overview of the temporal development of the characteristics. As the percentiles 3 and 97 describe a very small group of subjects, they can behave in a relatively unstable way.
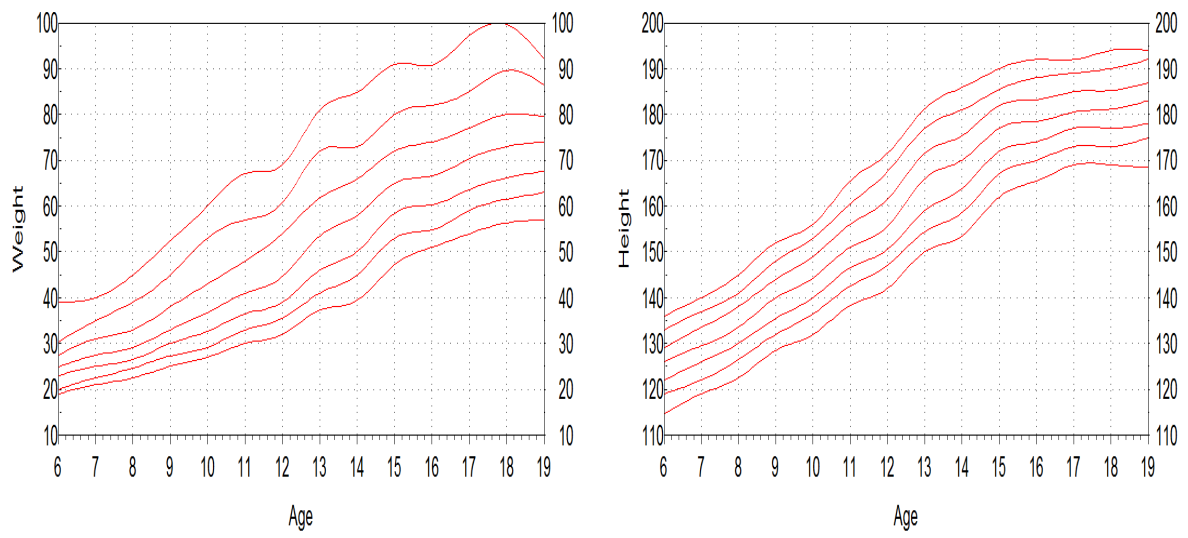

Figure 1. Graphs of centile splines of boys' height and weight
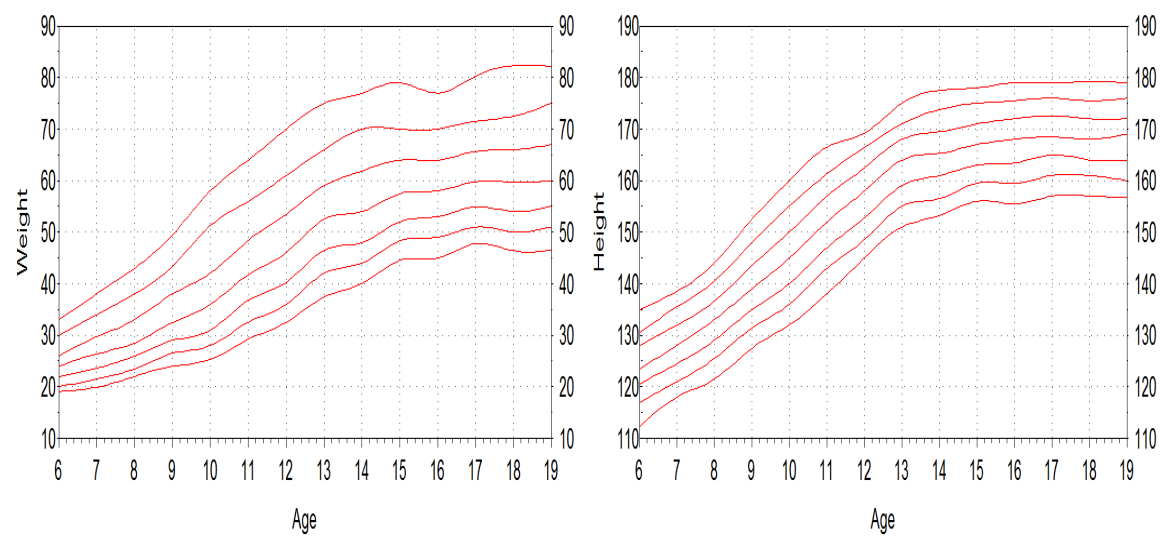

Figure 2. Graphs of centile splines of girls' height and weight 


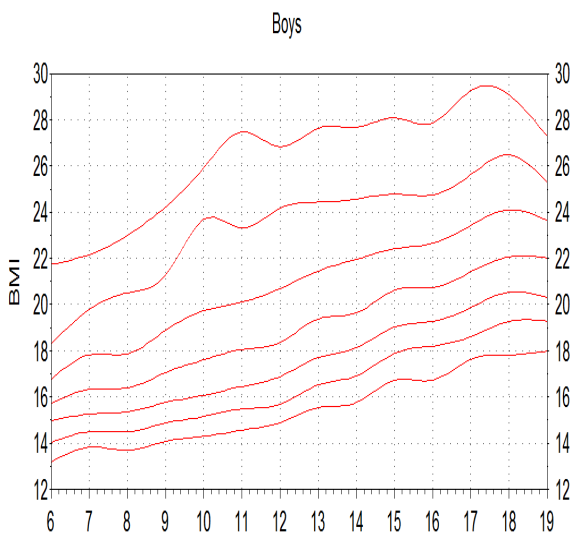

Age
Girls

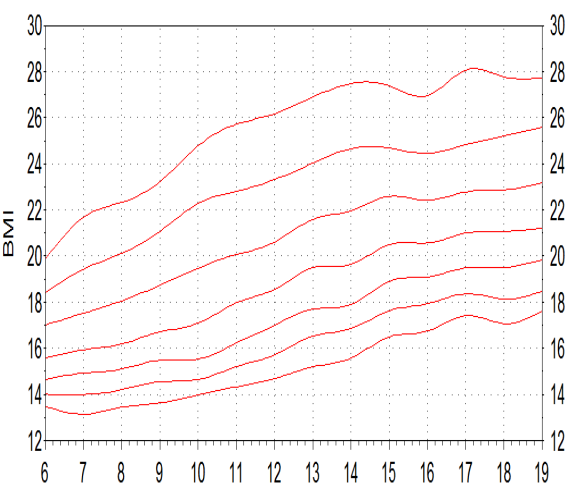

Age

Figure 3. Graphs of centile splines of boys' and girls' body mass index

Growth rate. Figure 4 presents the smoothed graphs of average growth rates at different ages. The girls' growth rate reaches its maximum at the age of 10-11 years, that of the boys at the age of 12-13 years. Compared to the growth rate graphs of 1966, the peaks have moved to approximately a year earlier in both sexes.

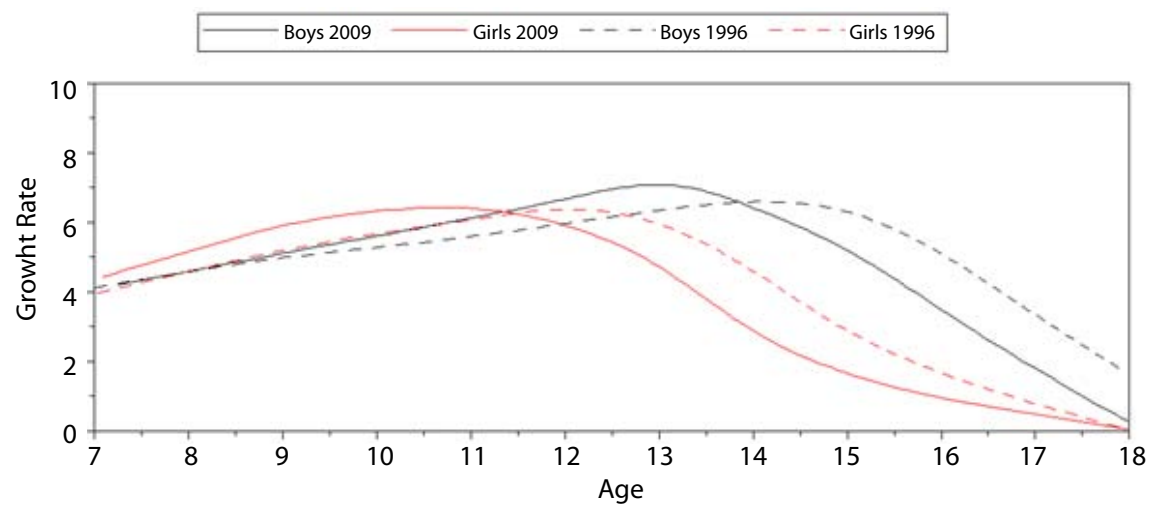

Figure 4. Boys' and girls' growth rates at different ages in 1996 and 2009 
Height. Figures 5 and 6 depict changes in boys' and girls' mean height during their school age. The results of the F-test and the t-test comparing the height of both sexes are given in Tables 4 and 5. The mean difference of height is $4.84 \mathrm{~cm}$ in boys and $3.86 \mathrm{~cm}$ in girls. The greatest changes have happened in boys at age 13 and in girls at age $11-8.71 \mathrm{~cm}$ and $7.50 \mathrm{~cm}$ respectively. The changes are statistically significant in children aged 6-17 years. In comparisons of dispersion only a few differences proved significant, generally the variability has remained at the same level.

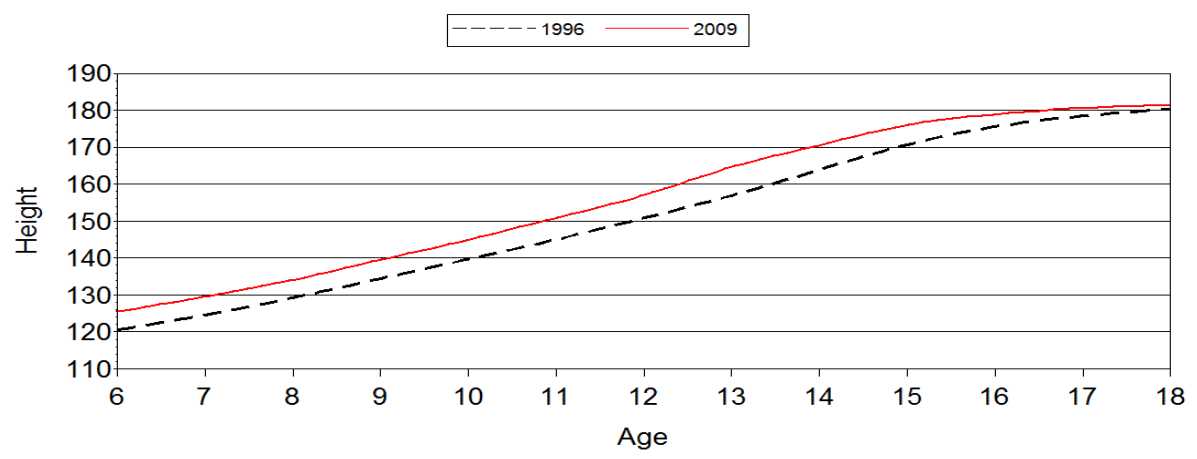

Figure 5. Comparison of boys' mean heights in 1996 and 2009

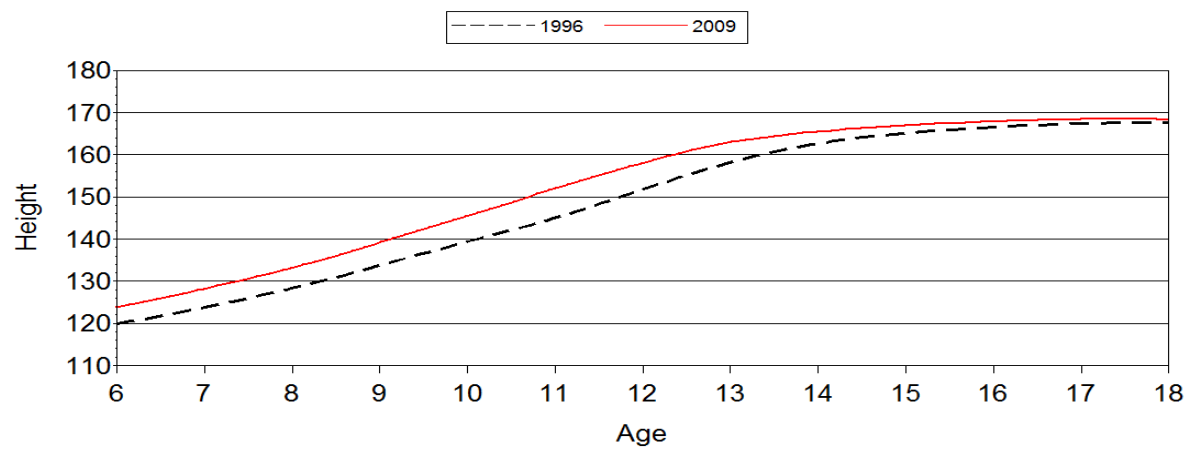

Figure 6. Comparison of girls' mean heights in 1996 and 2009 
Table 4. Results of the F-test and the t-test comparing boys' mean height

\begin{tabular}{ccccccccc}
\hline Age & $\begin{array}{c}\text { Mean } \\
(\mathbf{1 9 9 6 )}\end{array}$ & Std & $\begin{array}{c}\text { Mean } \\
\mathbf{( 2 0 0 9 )}\end{array}$ & Std & Difference & Std Err & Pr $>$ |t| & Pr $>\mathbf{F}$ \\
\hline 6 & 120.58 & 5.01 & 125.44 & 5.19 & 4.86 & 0.5969 & 0.0001 & 0.6539 \\
\hline 7 & 124.54 & 5.32 & 129.61 & 5.71 & 5.07 & 0.2996 & 0.0001 & 0.0659 \\
\hline 8 & 129.18 & 5.86 & 133.73 & 5.94 & 4.54 & 0.2833 & 0.0001 & 0.6863 \\
\hline 9 & 134.57 & 6.33 & 139.85 & 6.23 & 5.28 & 0.2779 & 0.0001 & 0.6106 \\
\hline 10 & 139.69 & 6.39 & 144.60 & 6.38 & 4.91 & 0.3623 & 0.0001 & 0.9767 \\
\hline 11 & 144.92 & 6.59 & 151.35 & 7.10 & 6.43 & 0.3131 & 0.0001 & 0.0212 \\
\hline 12 & 150.94 & 7.69 & 156.23 & 7.98 & 5.29 & 0.4198 & 0.0001 & 0.3270 \\
\hline 13 & 156.80 & 9.13 & 165.51 & 8.73 & 8.71 & 0.4038 & 0.0001 & 0.1608 \\
\hline 14 & 163.79 & 9.14 & 169.62 & 8.65 & 5.83 & 0.4871 & 0.0001 & 0.1551 \\
\hline 15 & 170.86 & 8.50 & 176.75 & 7.34 & 5.89 & 0.3649 & 0.0001 & 0.0001 \\
\hline 16 & 175.69 & 7.76 & 178.55 & 7.10 & 2.86 & 0.4365 & 0.0001 & 0.0327 \\
\hline 17 & 178.52 & 7.19 & 180.82 & 6.24 & 2.30 & 0.5617 & 0.0001 & 0.0170 \\
\hline 18 & 180.27 & 6.25 & 181.28 & 6.53 & 1.01 & 0.5480 & 0.0657 & 0.4813 \\
\hline
\end{tabular}

Table 5. The results of the F-test and the t-test comparing girls' mean height

\begin{tabular}{ccccccccc}
\hline Age & $\begin{array}{c}\text { Mean } \\
(\mathbf{1 9 9 6 )}\end{array}$ & Std & $\begin{array}{c}\text { Mean } \\
(\mathbf{2 0 0 9 )}\end{array}$ & Std & Difference & Std Err & Pr $>$ It| & Pr $>\mathbf{F}$ \\
\hline 6 & 119.89 & 5.59 & 123.79 & 5.60 & 3.90 & 0.6332 & 0.0001 & 0.9659 \\
\hline 7 & 123.80 & 5.04 & 128.24 & 5.60 & 4.44 & 0.2729 & 0.0001 & 0.0036 \\
\hline 8 & 128.20 & 5.71 & 132.89 & 5.92 & 4.69 & 0.2853 & 0.0001 & 0.2964 \\
\hline 9 & 133.76 & 6.06 & 139.45 & 6.44 & 5.69 & 0.2781 & 0.0001 & 0.0534 \\
\hline 10 & 139.61 & 7.11 & 145.13 & 7.47 & 5.52 & 0.4174 & 0.0001 & 0.2208 \\
\hline 11 & 144.66 & 7.40 & 152.16 & 7.28 & 7.50 & 0.3209 & 0.0001 & 0.5945 \\
\hline 12 & 151.79 & 7.95 & 157.70 & 6.90 & 5.91 & 0.4132 & 0.0001 & 0.0003 \\
\hline 13 & 158.15 & 7.48 & 163.39 & 6.43 & 5.24 & 0.3082 & 0.0001 & 0.0001 \\
\hline 14 & 162.94 & 7.00 & 165.20 & 6.54 & 2.26 & 0.3773 & 0.0001 & 0.0848 \\
\hline 15 & 164.92 & 6.12 & 167.13 & 5.95 & 2.21 & 0.2722 & 0.0001 & 0.3732 \\
\hline 16 & 166.59 & 6.21 & 167.63 & 6.24 & 1.04 & 0.3314 & 0.0017 & 0.9038 \\
\hline 17 & 167.41 & 5.90 & 168.62 & 5.88 & 1.21 & 0.3964 & 0.0023 & 0.9369 \\
\hline 18 & 167.62 & 5.54 & 168.23 & 5.88 & 0.61 & 0.3963 & 0.1241 & 0.2292 \\
\hline
\end{tabular}


Weight. The comparison of both boys' and girls' mean weight with the results of the previous study shows an increase (Figures 7 and 8). Tables 6 and 7 show the results of the F-test and the t-test comparing the weight in both sexes. The mean difference in weight is $5.90 \mathrm{~kg}$ in boys and $4.20 \mathrm{~kg}$ in girls. In boys, all the changes are statistically significant. In girls, they are significant at the ages of 6-16 years. The comparison of dispersions of boys' weight shows that dispersion has increased in all age groups and all the differences except two are statistically significant. In girls, dispersion has increased among the 6-11-year-olds.

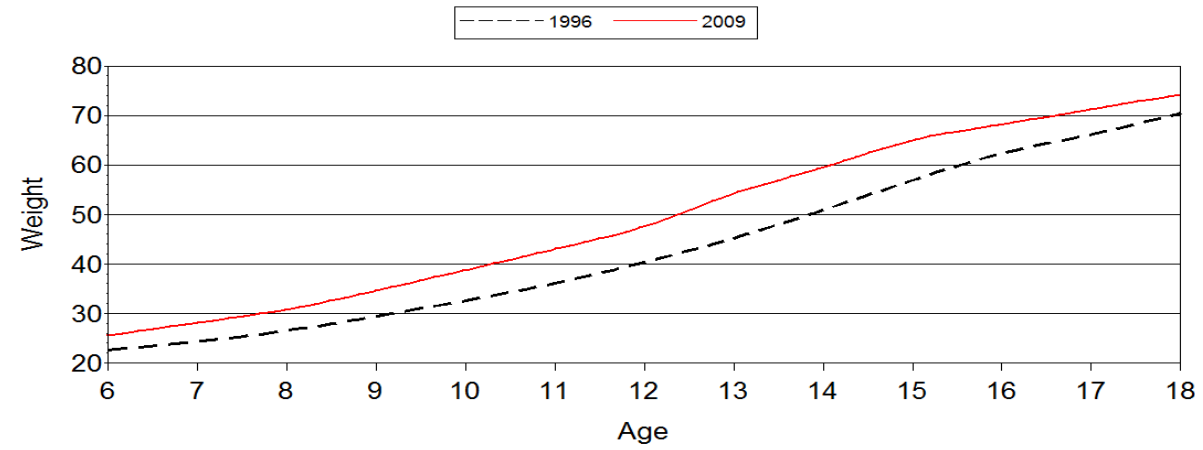

Figure 7. Comparison of boys' mean weights in 1996 and 2009

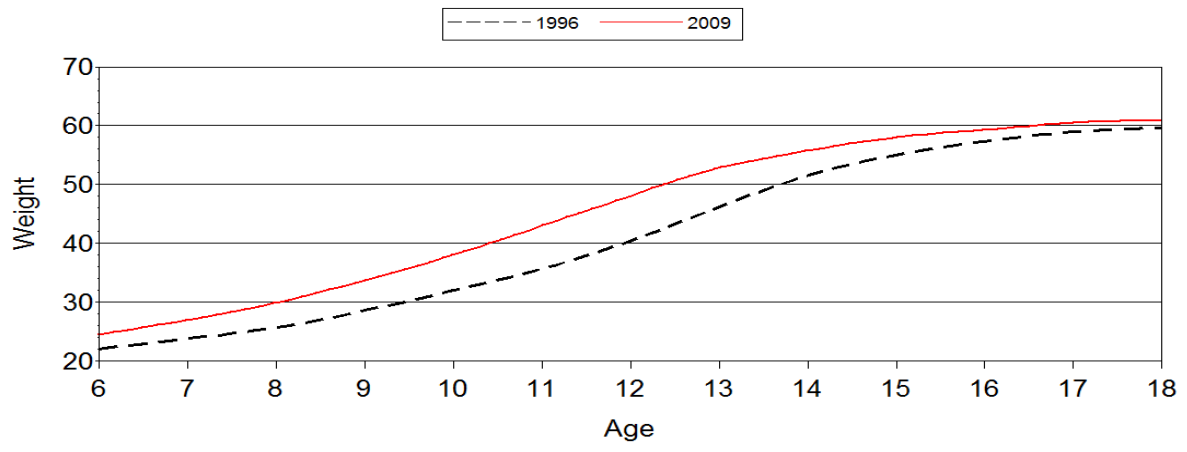

Figure 8. Comparison of girls' mean weights in 1996 and 2009 
Table 6. The results of the F-test and the t-test comparing boys' mean height

\begin{tabular}{ccccccccc}
\hline $\begin{array}{c}\text { Mean } \\
\text { Age }\end{array}$ & $\begin{array}{c}\text { (1996) } \\
6\end{array}$ & Std & $\begin{array}{c}\text { Mean } \\
\mathbf{( 2 0 0 9 )}\end{array}$ & Std & Difference & Std Err & Pr $>$ It & Pr $>$ F \\
\hline 7 & 24.66 & 2.93 & 25.45 & 4.32 & 2.79 & 0.3993 & 0.0001 & 0.0001 \\
\hline 8 & 26.36 & 3.84 & 30.51 & 5.93 & 4.15 & 0.2314 & 0.0001 & 0.0001 \\
\hline 9 & 29.52 & 4.73 & 34.70 & 7.19 & 5.18 & 0.2734 & 0.0001 & 0.0001 \\
\hline 10 & 32.60 & 5.45 & 38.76 & 8.63 & 6.16 & 0.3778 & 0.0001 & 0.0001 \\
\hline 11 & 36.04 & 6.31 & 43.24 & 9.74 & 7.20 & 0.3858 & 0.0001 & 0.0001 \\
\hline 12 & 40.34 & 8.24 & 46.91 & 10.36 & 6.57 & 0.4921 & 0.0001 & 0.0001 \\
\hline 13 & 45.19 & 9.75 & 55.06 & 11.81 & 9.87 & 0.5029 & 0.0001 & 0.0001 \\
\hline 14 & 50.84 & 9.91 & 58.59 & 11.56 & 7.75 & 0.5908 & 0.0001 & 0.0001 \\
\hline 15 & 56.84 & 9.63 & 65.84 & 10.94 & 9.00 & 0.5046 & 0.0001 & 0.0002 \\
\hline 16 & 62.72 & 10.27 & 67.59 & 10.59 & 4.87 & 0.6251 & 0.0001 & 0.4746 \\
\hline 17 & 65.82 & 9.59 & 71.50 & 11.10 & 5.68 & 0.8982 & 0.0001 & 0.0172 \\
\hline 18 & 70.57 & 8.69 & 74.12 & 11.06 & 3.55 & 0.8898 & 0.0001 & 0.0001 \\
\hline
\end{tabular}

Table 7. The results of the F-test and the t-test comparing girls' mean height

\begin{tabular}{ccccccccc}
\hline $\begin{array}{c}\text { Mean } \\
\text { Age }\end{array}$ & $\begin{array}{c}\text { (1996) } \\
\text { Std }\end{array}$ & $\begin{array}{l}\text { Mean } \\
\mathbf{( 2 0 0 9 )}\end{array}$ & Std & Difference & Std Err & Pr $>$ |tt & Pr $>$ F \\
\hline 6 & 22.07 & 3.25 & 24.46 & 3.73 & 2.39 & 0.3937 & 0.0001 & 0.0847 \\
\hline 7 & 23.92 & 3.56 & 27.05 & 4.85 & 3.13 & 0.2233 & 0.0001 & 0.0001 \\
\hline 8 & 25.45 & 3.97 & 29.73 & 5.65 & 4.28 & 0.2331 & 0.0001 & 0.0001 \\
\hline 9 & 28.62 & 4.92 & 33.83 & 6.75 & 5.21 & 0.2660 & 0.0001 & 0.0001 \\
\hline 10 & 32.09 & 6.08 & 37.88 & 8.89 & 5.79 & 0.4143 & 0.0001 & 0.0001 \\
\hline 11 & 35.51 & 7.19 & 43.13 & 9.28 & 7.62 & 0.3737 & 0.0001 & 0.0001 \\
\hline 12 & 40.35 & 8.88 & 47.77 & 9.76 & 7.42 & 0.5027 & 0.0001 & 0.0134 \\
\hline 13 & 46.12 & 9.43 & 53.26 & 9.56 & 7.14 & 0.4308 & 0.0001 & 0.6739 \\
\hline 14 & 51.62 & 9.61 & 55.38 & 10.01 & 3.76 & 0.5454 & 0.0001 & 0.3000 \\
\hline 15 & 55.07 & 9.34 & 58.44 & 8.90 & 3.37 & 0.4100 & 0.0001 & 0.1282 \\
\hline 16 & 57.24 & 8.32 & 58.87 & 8.35 & 1.63 & 0.4437 & 0.0002 & 0.9294 \\
\hline 17 & 59.12 & 8.46 & 60.84 & 8.57 & 1.72 & 0.5991 & 0.0042 & 0.4629 \\
\hline 18 & 59.56 & 8.23 & 60.76 & 9.15 & 1.20 & 0.6097 & 0.0396 & 0.0328 \\
\hline
\end{tabular}

Body mass index. Figures 9 and 10 illustrate boys' and girls' body mass indices compared to 1996. The results of the F-test and the t-test comparing the body mass indices are presented in Tables 8 and 9. In boys, the differences in 
mean BMIs are statistically significant in all age groups except the 6-year-olds. The changes are considerable - the mean difference is 1.30 units. The change is the greatest in the 10-year-olds. In girls, the changes are somewhat smaller than in boys - the mean difference is 0.99 units. The changes are statistically significant at ages 6-15. The comparisons of boys' BMI dispersion by F-tests show clear changes. Dispersion has increased in all age groups except the 16- and the 18-year-olds. In girls, the differences are statistically significant only at ages 7-11 years where dispersion has increased. In girls, the dispersion of body mass indices was quite high in the previous study already. This may be one of the reasons why the changes are not as great as in boys. Now the values of standard deviations are similar in both sexes.

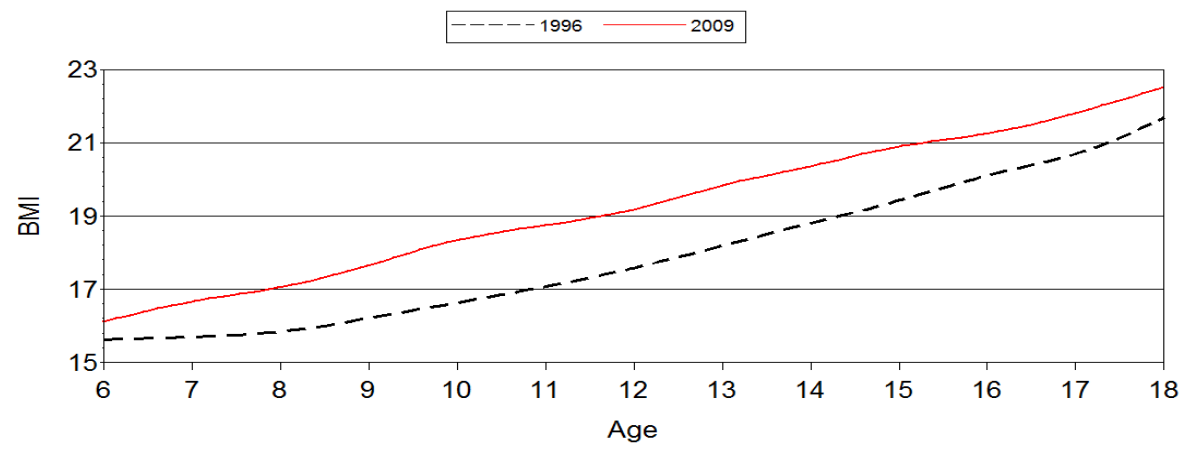

Figure 9. Comparison of boys' mean BMI in 1996 and 2009

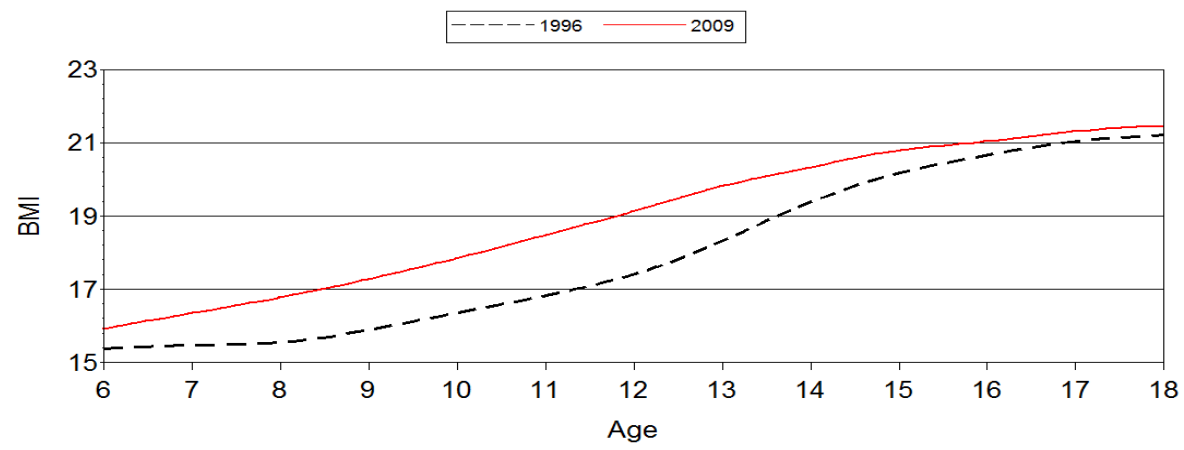

Figure 10. Comparison of girls' mean BMl in 1996 and 2009 
Table 8. The results of the F-test and the t-test comparing boys' mean BMI

\begin{tabular}{ccccccccc}
\hline Age & $\begin{array}{c}\text { Mean } \\
(\mathbf{1 9 9 6 )}\end{array}$ & Std & $\begin{array}{c}\text { Mean } \\
\mathbf{( 2 0 0 9 )}\end{array}$ & Std & Difference & Std Err & Pr $>$ It| & Pr $>\mathbf{F}$ \\
\hline 6 & 15.63 & 1.43 & 16.08 & 1.82 & 0.45 & 0.1847 & 0.0292 & 0.0031 \\
\hline 7 & 15.72 & 1.44 & 16.75 & 2.20 & 1.03 & 0.1054 & 0.0001 & 0.0001 \\
\hline 8 & 15.77 & 1.56 & 16.97 & 2.43 & 1.20 & 0.0947 & 0.0001 & 0.0001 \\
\hline 9 & 16.24 & 1.77 & 17.62 & 2.70 & 1.38 & 0.1026 & 0.0001 & 0.0001 \\
\hline 10 & 16.63 & 1.91 & 18.42 & 3.23 & 1.79 & 0.1374 & 0.0001 & 0.0001 \\
\hline 11 & 17.06 & 2.06 & 18.74 & 3.25 & 1.68 & 0.1282 & 0.0001 & 0.0001 \\
\hline 12 & 17.56 & 2.36 & 19.07 & 3.18 & 1.51 & 0.1463 & 0.0001 & 0.0001 \\
\hline 13 & 18.20 & 2.55 & 19.95 & 3.20 & 1.75 & 0.1350 & 0.0001 & 0.0001 \\
\hline 14 & 18.81 & 2.51 & 20.25 & 3.10 & 1.44 & 0.1562 & 0.0001 & 0.0001 \\
\hline 15 & 19.37 & 2.33 & 21.01 & 2.85 & 1.64 & 0.1294 & 0.0001 & 0.0001 \\
\hline 16 & 20.20 & 2.65 & 21.15 & 2.76 & 0.95 & 0.1624 & 0.0001 & 0.3423 \\
\hline 17 & 20.59 & 2.28 & 21.82 & 2.89 & 1.23 & 0.2278 & 0.0001 & 0.0001 \\
\hline 18 & 21.72 & 2.51 & 22.52 & 2.92 & 0.80 & 0.2391 & 0.0004 & 0.0150 \\
\hline
\end{tabular}

Table 9. The results of the F-test and the t-test comparing girls' mean BMI

\begin{tabular}{ccccccccc}
\hline $\begin{array}{c}\text { Mean } \\
\text { Age }\end{array}$ & $\mathbf{( 1 9 9 6 )}$ & Std & $\begin{array}{c}\text { Mean } \\
\mathbf{( 2 0 0 9 )}\end{array}$ & Std & Difference & Std Err & Pr $>$ Itl & Pr $>$ F \\
\hline 6 & 15.35 & 1.50 & 15.91 & 1.75 & 0.56 & 0.1836 & 0.0025 & 0.0545 \\
\hline 7 & 15.55 & 1.68 & 16.36 & 2.17 & 0.81 & 0.1015 & 0.0001 & 0.0001 \\
\hline 8 & 15.44 & 1.66 & 16.75 & 2.39 & 1.31 & 0.0981 & 0.0001 & 0.0001 \\
\hline 9 & 15.92 & 1.90 & 17.29 & 2.57 & 1.37 & 0.1018 & 0.0001 & 0.0001 \\
\hline 10 & 16.37 & 2.08 & 17.82 & 3.07 & 1.45 & 0.1424 & 0.0001 & 0.0001 \\
\hline 11 & 16.83 & 2.27 & 18.49 & 3.04 & 1.66 & 0.1213 & 0.0001 & 0.0001 \\
\hline 12 & 17.36 & 2.70 & 19.08 & 3.00 & 1.72 & 0.1541 & 0.0001 & 0.0060 \\
\hline 13 & 18.32 & 2.85 & 19.88 & 3.03 & 1.56 & 0.1344 & 0.0001 & 0.0584 \\
\hline 14 & 19.38 & 3.00 & 20.24 & 3.16 & 0.86 & 0.1715 & 0.0001 & 0.1872 \\
\hline 15 & 20.21 & 2.97 & 20.90 & 2.82 & 0.69 & 0.1302 & 0.0001 & 0.1026 \\
\hline 16 & 20.60 & 2.63 & 20.93 & 2.61 & 0.33 & 0.1393 & 0.0179 & 0.8338 \\
\hline 17 & 21.10 & 2.63 & 21.38 & 2.67 & 0.28 & 0.1788 & 0.1176 & 0.7580 \\
\hline 18 & 21.18 & 2.60 & 21.43 & 2.79 & 0.25 & 0.1875 & 0.1828 & 0.1545 \\
\hline
\end{tabular}

\section{CONCLUSIONS}

Estonian children's mean height has increased in both boys and girls in the age groups of 6-17-year-olds. Present-day children aged 18 years, however, are not taller than children in 1996. Thus, children have started to grow more quickly 
and reach their final height earlier. Dispersion has not changed, and there is reason to believe that the increase in height has been even in children with both quicker and slower growth rates.

In boys, mean height has increased in all age groups and in girls at the ages of 6-16 years. The range of changes is also noteworthy. As a comparison, it can be said that between the studies conducted in 1956 and 1996, the changes in mean body mass were $0.5-2 \mathrm{~kg}$. Thus, Estonian schoolchildren have become considerably heavier. In boys, the dispersion of weights has increased in nearly all age groups and in girls at ages $7-11$.

The mean body mass index has increased in boys aged 7-18 years and in girls aged 6-16 years. The changes are considerable. Consequently, the schoolchildren have become stronger and more corpulent in their body build. The increase of dispersion in nearly all age groups of boys suggests that the proportion of children with big BMI has grown.

The results of the study lead to the conclusion that children's physical development is quicker nowadays. Therefore, the mean height and weight have increased in all age groups. In relation to height, the increase in weight has been quicker, and this is reflected in the increase of the body mass index. Nearly all the changes are statistically significant; thus, the Estonian children do not correspond well to the standards of 1996 . The need for updating the growth charts is statistically substantiated. The results confirm the results of earlier analysis based on a similar dataset [2].

\section{REFERENCES}

1. Grünberg, H., Adojaan B., Thetloff, M. (1998). Kasvamine ja kasvuhäired: metoodiline juhend laste füüsilise arengu hindamiseks. [Growth and growth disorders: Methodological instructions for assessment of children's physical development] Tartu: Tartu University Press, 2012 (in Estonian).

2. Koskel, S., Tiit, E.-M., Kaarma, H. (2010). Changes in Estonian School students' height and weight in the last ten years. - Papers on Anthropology, 19, 211-229.

\section{Address for correspondence:}

Helje Kaarma Dr. Sc., Dr. med.

Centre for Physical Anthropology

Institute of Anatomy

Faculty of Medicine

University of Tartu

E-mail: antrop@ut.ee 